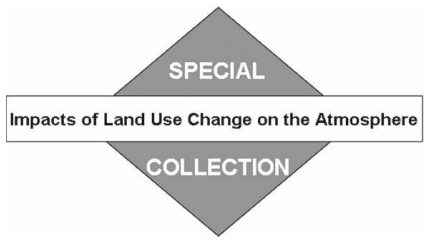

\title{
An Urban Parameterization for a Global Climate Model. Part II: Sensitivity to Input Parameters and the Simulated Urban Heat Island in Offline Simulations
}

\author{
K. W. Oleson and G. B. Bonan \\ Climate and Global Dynamics Division, National Center for Atmospheric Research,* Boulder, Colorado \\ J. FEDDEMA \\ Department of Geography, University of Kansas, Lawrence, Kansas \\ M. VERTENSTEIN \\ Climate and Global Dynamics Division, National Center for Atmospheric Research, ${ }^{*}$ Boulder, Colorado
}

(Manuscript received 25 September 2006, in final form 31 July 2007)

\begin{abstract}
In a companion paper, the authors presented a formulation and evaluation of an urban parameterization designed to represent the urban energy balance in the Community Land Model. Here the robustness of the model is tested through sensitivity studies and the model's ability to simulate urban heat islands in different environments is evaluated. Findings show that heat storage and sensible heat flux are most sensitive to uncertainties in the input parameters within the atmospheric and surface conditions considered here. The sensitivity studies suggest that attention should be paid not only to characterizing accurately the structure of the urban area (e.g., height-to-width ratio) but also to ensuring that the input data reflect the thermal admittance properties of each of the city surfaces. Simulations of the urban heat island show that the urban model is able to capture typical observed characteristics of urban climates qualitatively. In particular, the model produces a significant heat island that increases with height-to-width ratio. In urban areas, daily minimum temperatures increase more than daily maximum temperatures, resulting in a reduced diurnal temperature range relative to equivalent rural environments. The magnitude and timing of the heat island vary tremendously depending on the prevailing meteorological conditions and the characteristics of surrounding rural environments. The model also correctly increases the Bowen ratio and canopy air temperatures of urban systems as impervious fraction increases. In general, these findings are in agreement with those observed for real urban ecosystems. Thus, the model appears to be a useful tool for examining the nature of the urban climate within the framework of global climate models.
\end{abstract}

\section{Introduction}

Urban ecosystems can significantly alter the radiative, thermal, moisture, and aerodynamic characteristics of the land surface (Landsberg 1981; Oke 1987; Bonan 2002; Arnfield 2003). As a consequence of these changes, urban climates can differ significantly from surrounding natural ecosystems, often resulting in ur-

* The National Center for Atmospheric Research is sponsored by the National Science Foundation.

Corresponding author address: Keith Oleson, National Center for Atmospheric Research, P.O. Box 3000, Boulder, CO 803073000.

E-mail: oleson@ucar.edu ban heat islands (e.g., Landsberg 1981). The simulation of urban climate impacts requires two major components: 1) the representation of the physical processes controlling energy and water fluxes and 2) the characterization of urban morphology and urban materials with respect to aerodynamic, radiative, and heat transfer properties (e.g., Terjung and O'Rourke 1980; Arnfield 2000; Masson 2000; Grimmond and Oke 2002; Martilli et al. 2002; Best 2005; Oleson et al. 2008, hereinafter Part I). We have developed an urban parameterization to simulate urban systems on a global scale (Part I) under a wide variety of climate and surface conditions. The urban model is integrated with the Community Land Model, version 3 (CLM3; Oleson et al. 2004; Dickinson et al. 2006).

Our model has been evaluated for two urban sites 
described in Part I, but further evaluation is needed before the model can be used to investigate global urban climate questions. Thus, the purpose of this paper is twofold. First, the robustness of the model is examined through sensitivity studies: the sensitivity of the model fluxes to morphological, radiative, and thermal parameters, with respect to observations for the Mexico City, Mexico, and Vancouver, Canada, sites described in Part I, is assessed. These studies also provide guidance for the development of urban databases to extend the model beyond flux tower footprints to larger spatial scales because some ordering of the relative importance of parameters can be identified. Second, some general characteristics of the urban climate produced by the model are examined, with a focus on the characteristics of the simulated heat island. We examine the roles that urban morphology, anthropogenic heat, pervious surfaces, and rural environment play in determining heat island characteristics.

\section{Sensitivity to input parameters}

The sensitivity of the model is quantified for three subsets of the input parameters. The subsets are morphological parameters (height-to-width ratio, roof fraction, pervious road fraction, building height, roof thickness, and wall thickness), and physical parameters subdivided into radiative (emissivity and albedo of roof, road, and wall) and thermal parameters (thermal conductivity and heat capacity of roof, wall, and road, and soil texture as defined by percent sand and percent clay, which affect thermal conductivity and heat capacity). Each parameter is perturbed by $\pm 20 \%$ from the values used in simulations of Mexico City and Vancouver (Tables 1, 2, and 3 in Part I) and all possible combinations of parameters and their perturbed values within a subset are simulated. Thus, $2^{6}=64$ simulations are performed for the morphological subset, and $2^{6}=64$ and $2^{8}=256$ simulations are performed for the radiative and thermal subsets, respectively.

Simulations are conducted for 2-7 December 1993 (Mexico City) and 20-24 August 1992 (Vancouver). The observed fluxes for Mexico City and Vancouver are from Oke et al. (1999) and Voogt and Grimmond (2000), respectively. The time frequency of the observed and modeled data is hourly, which permits analysis of the diurnal cycle. Note that some of the parameter perturbations may be less than $\pm 20 \%$ because of physical constraints (e.g., emissivities must be less than 1.0).

The results are displayed in Taylor diagrams for convenience (Taylor 2001). Figure 1 shows the sensitivity of simulated net radiation and sensible, latent, and stor- age heat fluxes to morphological, radiative, and thermal parameters for Mexico City. The symbols show the model performance using the baseline parameters as discussed in Part I, and each additional point represents one sensitivity simulation. These diagrams characterize three aspects of the degree of similarity between the simulated and observed fields. First, the radial distance from the origin to the points or symbols represents the standard deviation of the model field normalized by the standard deviation of the observations $\left(\sigma_{m} / \sigma_{o}\right)$. The degree of departure from a value of one may be interpreted as indicating errors in the amplitude of the diurnal cycle. Second, the azimuthal position of the points or symbols represents the correlation $r$ between the two fields. This may be interpreted as indicating errors due to incorrect phasing of the diurnal cycle. Third, a line drawn from the point corresponding to $\sigma_{m} / \sigma_{o}=1$ and $r=1$ (denoted by "REF" in the figures) to a point or symbol represents the "centered pattern" root-meansquare error (RMSE), which is the RMSE once the overall bias has been removed.

Net radiation is least sensitive to uncertainties in morphological parameters, followed by latent, storage, and sensible heat fluxes (Fig. 1a). For net radiation, two groups of points are evident that pertain to changes in the roof fraction. An increase in the roof fraction from the default value results in a very small improvement in the amplitude of the diurnal cycle (as indicated by the standardized deviation) while slightly degrading the phase (as indicated by the correlation coefficient), resulting in a slight decrease in the RMSE. A decrease in the roof fraction has the opposite effect. The latent heat flux also exhibits relatively small sensitivity to morphological parameters primarily because it is such a small component of the energy budget. The simulation that corresponds to the greatest improvement in amplitude of latent heat consists of changes in morphological parameters that effectively increase the area and thus the influence of the pervious road fraction. These changes are both direct (increase in the pervious road fraction) and indirect (decreases in height-to-width ratio, roof fraction). Degradation in amplitude occurs for changes that decrease the influence of the pervious road fraction. Note that the phase of latent heat flux is not affected by uncertainties in morphological parameters because the temporal variability of latent heat flux is controlled by sources not modeled here-that is, vehicle combustion, air-conditioning, and street washing (Oke et al. 1999).

The simulation of storage heat flux is very stable with respect to morphology. Neither the phase nor the amplitude change much, and they remain well simulated. The amplitude of sensible heat flux is more 

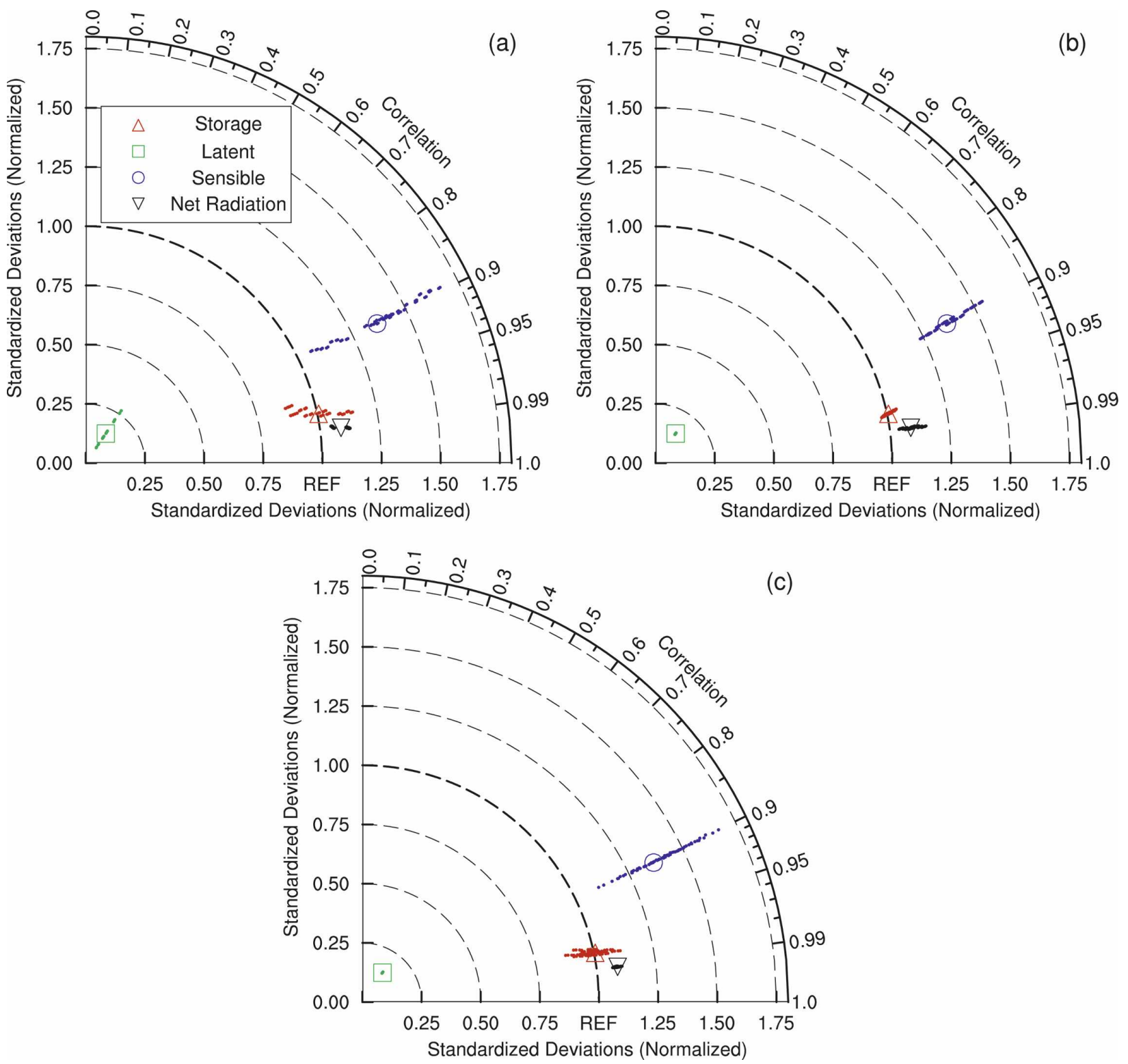

FIG. 1. Sensitivity of hourly net radiation (black) and storage (red), sensible (blue), and latent (green) heat fluxes to $\pm 20 \%$ uncertainty in (a) morphological parameters, (b) radiative parameters, and (c) thermal parameters for the Mexico City site (Me93) for days 336-341 (2-7 Dec 1993). The symbols (inverted triangle = net radiation; triangle = storage heat; circle = sensible heat; square = latent heat) show the model performance using the baseline parameters in Part I, and each additional point represents one sensitivity simulation.

strongly affected by morphology, although the phase is very stable. Some insight into the sensitivity of these fluxes can be gained by examining the model response in the extremes. Figures $2 \mathrm{a}, \mathrm{b}$ show the average diurnal cycle of sensible and storage heat flux for the control (CLM3) in comparison with observations and two sensitivity simulations (SENS_MORPH1 and SENS_MORPH2). The two sensitivity simulations correspond to the points in Fig. 1a that have the minimum and maximum $\sigma_{m} / \sigma_{o}$ in sensible heat flux [1.06
(SENS_MORPH1) and 1.67 (SENS_MORPH2), respectively]. These two points correspond to those with opposite extremes of storage heat flux (maximum and minimum $\sigma_{m} / \sigma_{o}$ ). The SENS_MORPH1 simulation has a combination of parameter perturbations that result in an increase in the amplitude of storage heat flux and a decrease in sensible heat flux (increases in height-towidth ratio, wall and roof thicknesses, and pervious road fraction, and a decrease in roof fraction). Parameter changes in the opposite direction produce a de- 
Sensible Heat Flux

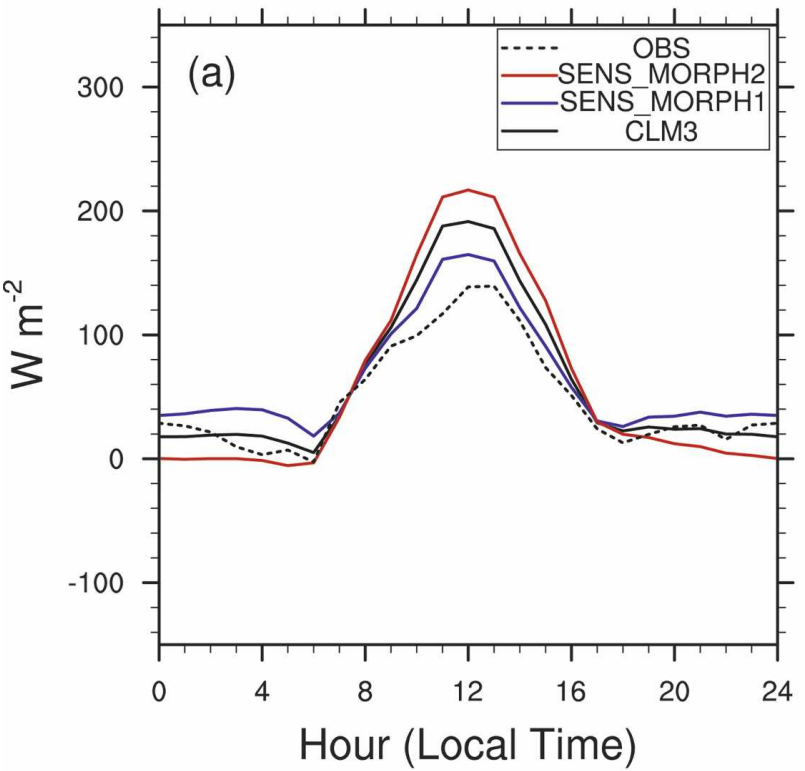

Sensible Heat Flux

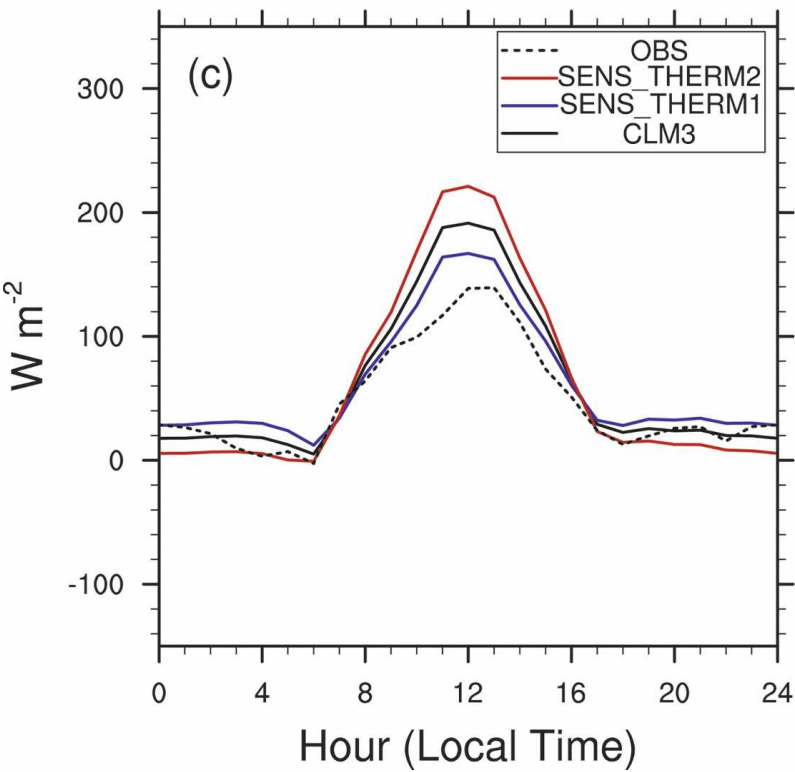

Storage Heat Flux

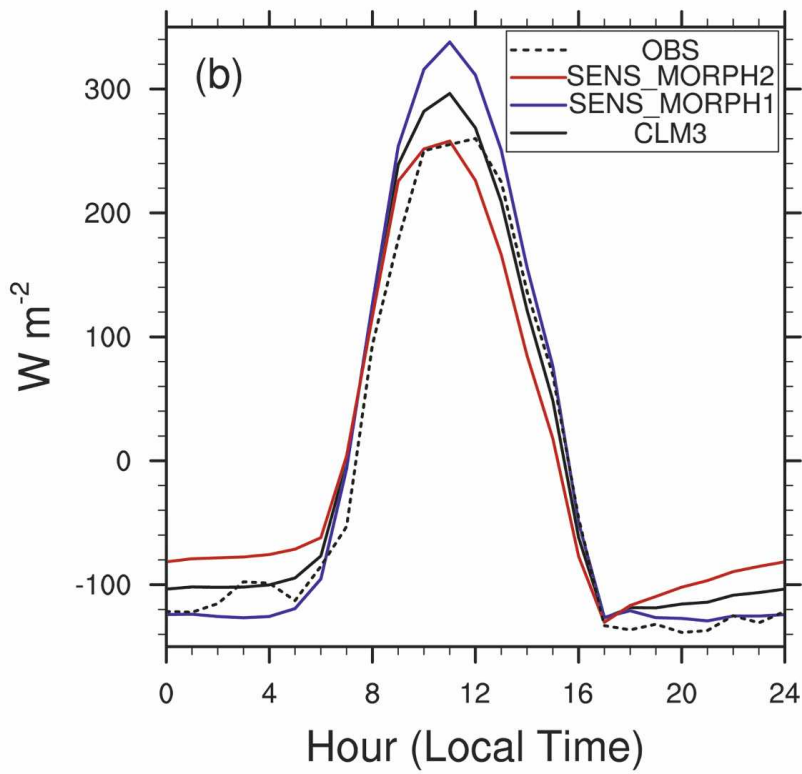

Storage Heat Flux

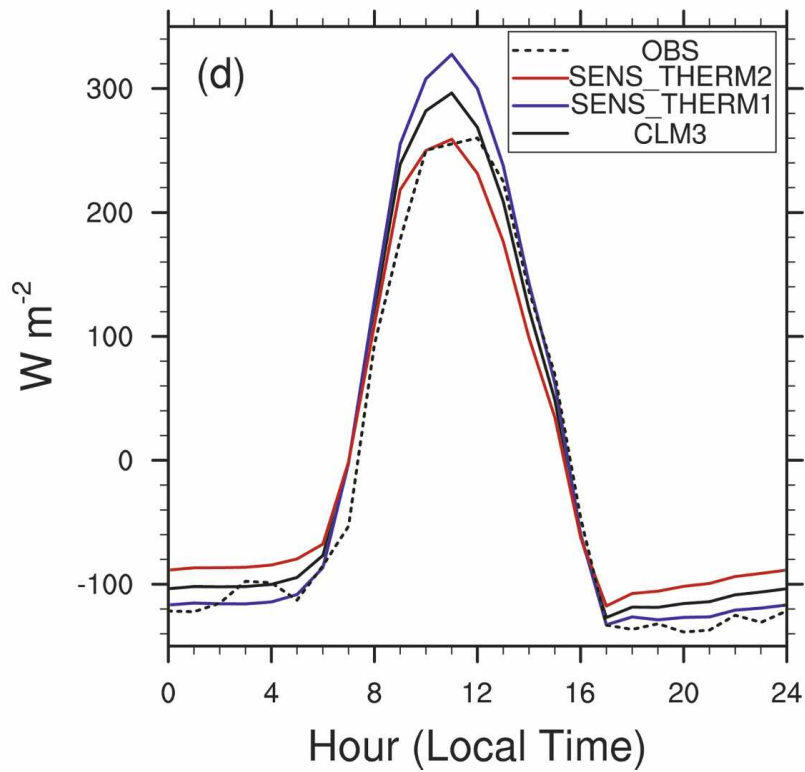

FIG. 2. Average diurnal cycle of simulated (solid lines) and observed (dashed lines) (a), (c) sensible and (b), (d) storage heat fluxes for Me93 for days 336-341 (2-7 Dec 1993). The black solid line shows the model performance using the baseline parameters in Part I, SENS_MORPH1 and SENS_MORPH2 correspond to the points in Fig. 1a that have the minimum and maximum normalized standardized deviations in sensible heat flux (1.06 and 1.67, respectively), and SENS_THERM1 and SENS_THERM2 correspond to the points in Fig. 1c that have the minimum and maximum normalized standardized deviations in sensible heat flux (1.11 and 1.67, respectively).

crease in storage and an increase in sensible heat in the SENS_MORPH2 simulation. Although the daytime peak of storage heat flux is close to observed in the SENS_MORPH2 simulation, the nighttime release of heat is too weak. In addition, the phase degrades somewhat, as indicated by the reduced $r$ (Fig. 1a).
Net radiation is also relatively insensitive to uncertainty in radiative and thermal parameters (Fig. 1b,c). The radiative parameters induce the largest model response with decreases in emissivity and albedo resulting in a small degradation in the amplitude of the diurnal cycle and the increases in these parameters resulting in 
a small model improvement. Latent heat flux is insensitive to both radiative and thermal parameters. Storage and sensible heat fluxes are less sensitive to radiative than to thermal parameters. Decreases in emissivity and albedo increase net radiation and result in an increase in the amplitude of sensible heat flux, and vice versa. However, these changes are relatively small and only affect the amplitude of the diurnal cycle, with the phase being unchanged.

The model sensitivity to thermal parameters is comparable to its sensitivity to morphological parameters. Figures $2 \mathrm{c}, \mathrm{d}$ show the model sensible and storage heat response with extreme settings for thermal parameters. The simulation SENS_THERM1 produces a minimum in $\sigma_{m} / \sigma_{o}$ for sensible heat, and SENS_THERM2 produces a maximum. The maximum in $\sigma_{m} / \sigma_{o}$ for sensible heat is produced by combinations of parameter changes that decrease thermal admittance of the roof, wall, and road surfaces; decreases in thermal conductivity and heat capacity for roof, wall, and impervious road; and increases/decreases in sand/clay content, which maximizes the thermal conductivity of the mineral soil underlying the pervious and impervious road. As before, an increase in the amplitude of sensible heat results in a decrease in storage heat and vice versa. The phase of storage heat flux exhibits more sensitivity to thermal parameters than does sensible heat flux.

The simulated fluxes for Vancouver exhibit the same sensitivity characteristics as the Mexico City site but in general are less sensitive (Fig. 3). A small exception to this is the sensitivity of latent heat flux to morphological parameters. At this site, the pervious road fraction is greater and thus plays a larger role in the energy balance. As in the Mexico City simulations, the amplitude of the diurnal cycle of latent heat increases with changes in morphological parameters that effectively increase the area of the pervious road fraction.

Sensible and storage heat flux at the Vancouver site exhibit fairly equal sensitivity in terms of amplitude within each of the three subsets of parameters. This is in contrast to the Mexico City study, in which sensible heat flux exhibited the most sensitivity. This is simply because the standard deviation of the storage heat flux at the Mexico City site is nearly 2 times that of sensible heat. As noted by Oke et al. (1999), conduction dominates over convection at this site. In contrast, the Vancouver sensible and storage heat flux standard deviations are more nearly equal. Because net radiation and latent heat flux are nearly unchanged and because energy must be conserved, changes in sensible heat must be offset by storage changes of the same magnitude. The lower sensitivity of these fluxes to morphological parameters at the Vancouver site also is likely due to the fact that the changes in the height-to-width ratio and the wall thickness are much smaller than for the Mexico City site because the default values are small. The roof fraction and thickness changes are similar between the two sites. Vancouver fluxes exhibit little sensitivity to changes in radiative parameters, probably because the perturbations to roof albedo are smaller.

\section{The urban heat island}

Relationships between heat island intensity and city size have been proposed in the literature. Oke (1973) derived a statistical relationship between average survey heat island intensity and city size as measured by population for 10 settlements on the St. Lawrence lowland in Canada. The logarithmic relationship explained $97 \%$ of the data variance, thus supporting the hypothesis that heat island intensity is related to city size. A similar relationship was found for maximum heat island intensity as a function of population. Different regression coefficients were required for North American and European settlements because European settlements were found to have smaller heat islands for a given city size. Oke (1981) extended this study and discovered that the North American and European datasets could be merged into a single relationship by regressing maximum heat island intensity against sky-view factor or height-to-width ratio $H / W$. This relationship, shown in Fig. 4, is

$$
\Delta T_{u-r(\max )}=7.45+3.97 \ln (H / W) .
$$

To investigate the model's ability to reproduce this relationship, the model was run for a single North American site for $1 \mathrm{yr}$ at height-to-width ratios from 0.5 to 3.0 [uncoupled from an atmospheric model and forced by observations of atmospheric variables as in Bonan et al. (2002)]. In the absence of observed U.S. city characteristics to model this relationship, some assumptions were made. Morphological parameters were subjectively chosen to represent the average characteristics of the core of a medium-size city (Table 1). Roof, wall, and road materials and their thermal properties were adapted from the Vancouver site because these materials are more likely to be representative of the properties of U.S. cities than would be those of the Mexico City site (Table 2). A layer of insulation was added to the walls to reflect the insulative character of U.S. buildings. The volumetric heat capacity for dense concrete was set to 2.11 for both walls and roofs to be consistent [this value was 2.11 for dense concrete at the Vancouver site, except for the roof, for which it was set to 2.21 based on Masson et al. (2002)]. Radiative parameters were set to the values that were used in Part I to demonstrate the radiative characteristics of the 

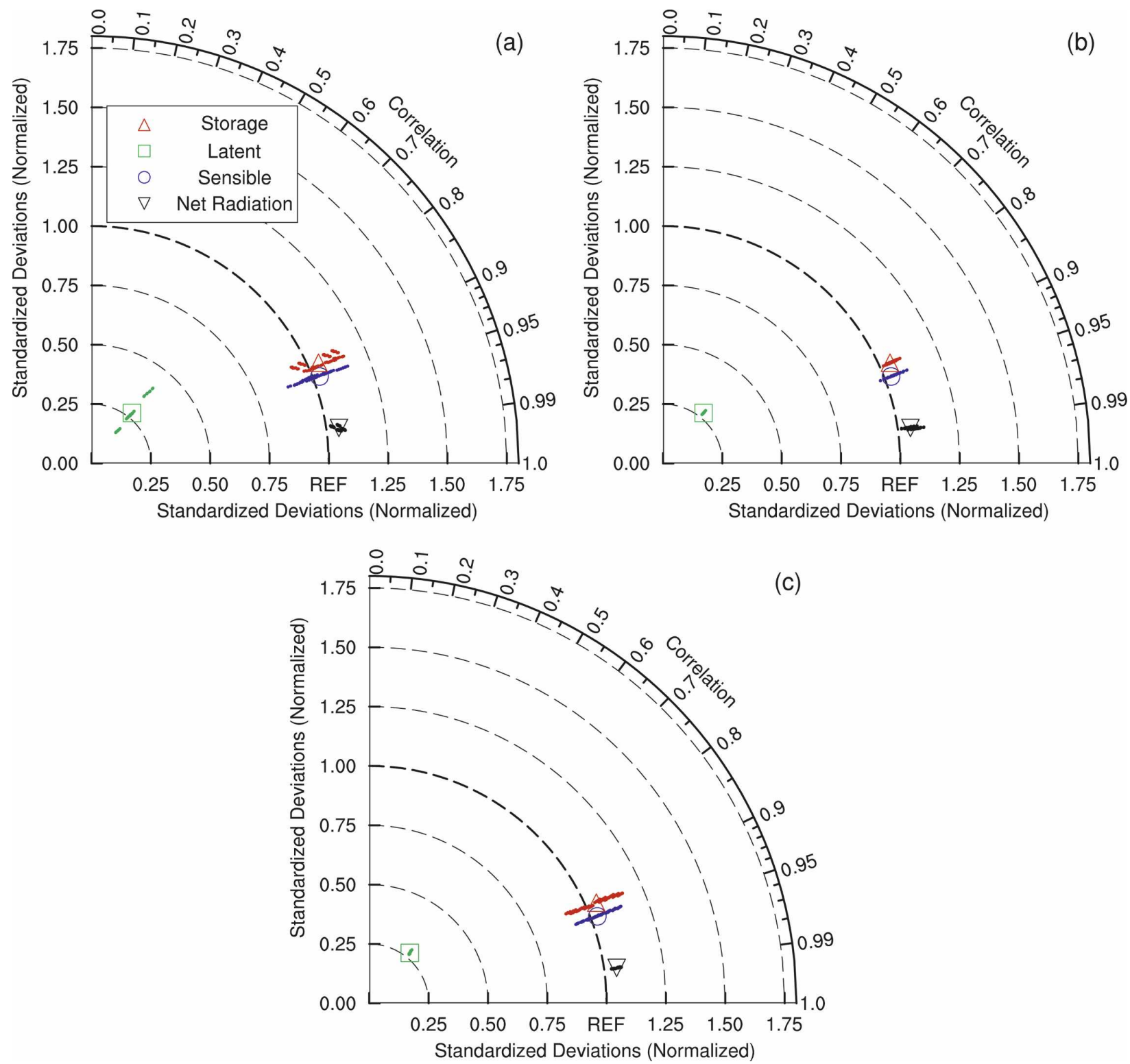

FIG. 3. As in Fig. 1, but for the Vancouver site (V192) for days 232-236 (20-24 Aug 1992).

model (Table 3). These properties are illustrative only and are not meant to represent any specific U.S. city.

Maximum heat islands may be expected to occur under urban conditions of little to no latent heat; therefore, the fraction of pervious road was set to zero. Simulations were conducted with and without anthropogenic heat fluxes. A representative diurnal profile of traffic heat flux was calculated based on Sailor and $\mathrm{Lu}$ (2004). Hourly anthropogenic heat fluxes for a typical large U.S. city were summed to yield a total daily anthropogenic heat flux. Traffic heat flux was assumed to contribute $50 \%$ to this flux (Sailor and Lu 2004). The total traffic heat flux was distributed diurnally using the national fractional traffic profile given by Sailor and $\mathrm{Lu}$ (2004). Because this traffic flux is from a city-average analysis, it was assumed that this traffic profile is representative of a height-to-width ratio $H / W$ of 0.5 , a reasonable large-city average value. The traffic flux was scaled by $H / W$ based on the observation that anthropogenic heat fluxes are often an order of magnitude higher in urban cores (Sailor and Lu 2004; e.g., $H / W=$ 3.0), so that

$$
H_{\text {traffic }}(H / W, h)=f_{\text {traffic }} H_{\text {traffic }}(H / W=0.5, h),
$$

where $H_{\text {traffic }}(H / W, h)$ is the traffic heat flux for a given height-to-width ratio at hour $h, H_{\text {traffic }}(H / W=0.5, h)$ is 


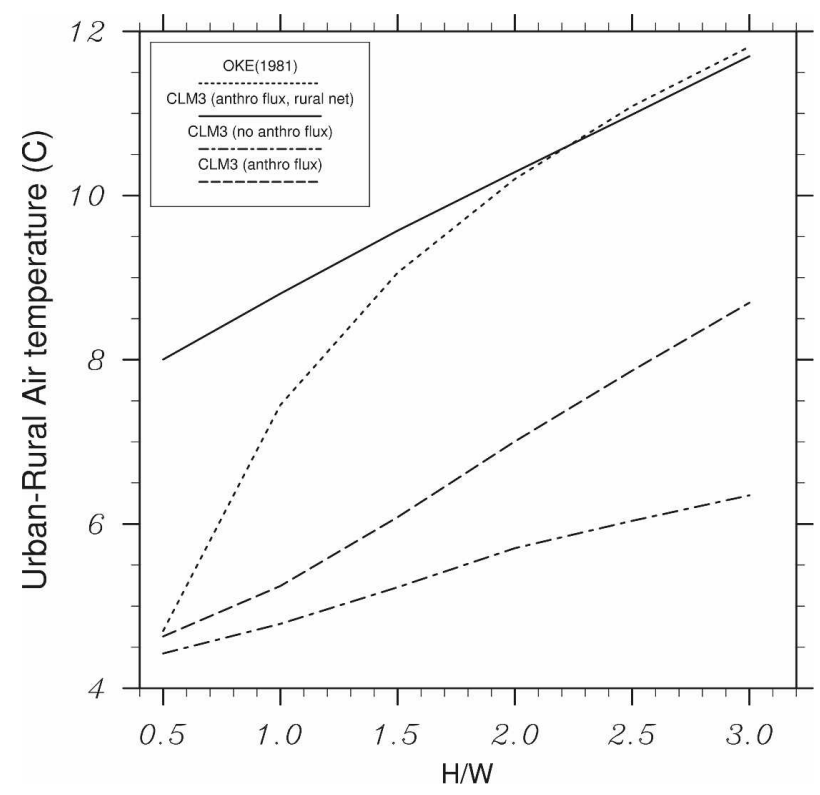

FIG. 4. Maximum annual heat island intensity (urban minus rural air temperature) produced by the urban model for a North American midlatitude site $\left(40^{\circ} \mathrm{N}, 75^{\circ} \mathrm{W}\right)$ in comparison with Oke (1981) [Eq. (1)]. Model results are shown for no anthropogenic flux (labeled "no anthro flux"), with anthropogenic flux ("anthro flux"), and with anthropogenic flux and rural site modeled as needleleaf evergreen tree ("anthro flux, rural net").

the hourly traffic profile derived above, and the factor $f_{\text {traffic }}$ is

$$
f_{\text {traffic }}=3.6(H / W-0.5)+1 .
$$

The waste heat from domestic heating/cooling $H_{\text {wasteheat }}$ was parameterized directly from the amount of energy required to keep the internal building temperature between prescribed maximum $(297.6 \mathrm{~K})$ and minimum $(291.2 \mathrm{~K})$ values, assuming $50 \%$ efficiency of the heating/cooling systems. The energy is calculated by using the internal building temperature as a bottom boundary condition in the solution of the heat conduction equation (Oleson et al. 2004). The total waste heat is generated by roof and sunlit and shaded walls as represented in our urban canyon model:

$$
\begin{aligned}
H_{\text {wasteheat }}= & 2\left[W_{\text {roof }} H_{\text {wasteheat,roof }}+\left(1-W_{\text {roof }}\right)\right. \\
& \left.\times\left(H_{\text {wasteheat,sunwall }}+H_{\text {wasteheat,shdwall }}\right) H / W\right],
\end{aligned}
$$

where $W_{\text {roof }}$ is the roof fraction. The sum of $H_{\text {traffic }}$ and $H_{\text {wasteheat }}$ is the prescribed anthropogenic flux. A separate simulation using a rural surface consisting of grassland was used to estimate the heat island intensity. Heat island intensity is computed from the urban-minusrural air temperature difference, where urban air temperature is the urban canopy layer (UCL) air tempera-
TABLE 1. Morphological input data required for the urban model.

\begin{tabular}{llc}
\hline \multicolumn{1}{c}{ Data } & Symbol & Default value \\
\hline Canyon height-to-width ratio & $H / W$ & $0.5-3.0$ \\
Roof fraction & $W_{\text {roof }}$ & 0.25 \\
Pervious road fraction & $f_{\text {prvrd }}$ & 0.0 \\
Roof thickness (m) & $\Delta z_{\text {roof }}$ & 0.2 \\
Wall thickness (m) & $\Delta z_{\text {walls }}$ & 0.2 \\
Building height (m) & $H$ & 10 \\
Impervious road thickness* $(\mathrm{m})$ & $\Delta z_{\text {imprvrd }}$ & 0.15 \\
\hline
\end{tabular}

* The impervious road is underlain by soil.

ture (Part I) and the rural air temperature is the 2-m air temperature diagnostic in CLM3 (Oleson et al. 2004).

The maximum annual heat island intensity produced by the model is compared with Oke's relationship in Fig. 4. In agreement with Oke's relationship, the urban model produces a heat island intensity that increases with height-to-width ratio. At a height-to-width ratio of one-half, the heat island produced by the model compares favorably to Oke's value, whether or not anthropogenic fluxes are included. However, the model's heat island increases with height-to-width ratio at a slower rate than in Oke's relationship, and the increase is nearly linear with height-to-width ratio in contrast to the observed nonlinear relationship. Adding anthropogenic fluxes to the urban model improves the comparison, but the heat island is still weaker relative to observations.

One probable reason for this discrepancy is the nature of the offline experimental setup. The rural and urban surfaces are forced with identical atmospheric variables. In particular, the atmospheric temperature at the forcing height is prescribed identically over the two surfaces. Because the atmospheric temperature is linked to the UCL and rural air temperatures through the aerodynamic resistance for heat, the difference in air temperature between the two surfaces is suppressed. In reality, the urban boundary layer responds to the UCL so that the UCL heat island is accompanied by an urban boundary layer heat island (Oke 1976). The simulated downwelling longwave radiation is also the same over both surfaces. However, an urban "greenhouse" effect is known to exist as a result of the combined effects of pollution, humidity differences, and warmer urban atmospheric temperature (Oke et al. 1991). This increases the downwelling longwave radiation over urban surfaces as compared with rural surfaces. However, it has been shown this has relatively small effects on the heat island (Oke et al. 1991). Furthermore, the attenuation of solar radiation by the urban atmosphere may offset the increased longwave (Oke 1988). 
TABLE 2. Thermal input data required for the urban model. Thermal parameters of the soil for the pervious road and the soil underlying the impervious road are determined from soil texture (Oleson et al. 2004).

\begin{tabular}{|c|c|c|}
\hline Data & Symbol & Default value \\
\hline Roof thermal conductivity $\left(\mathrm{W} \mathrm{m}{ }^{-1} \mathrm{~K}^{-1}\right)$ & $\lambda_{\text {roof }, i}$ & $\begin{aligned} i & =1, \ldots, 6: 1.4 \text { (gravel) } \\
i & =7: 0.03 \text { (insulation) } \\
i & =8, \ldots, 10: 1.51 \text { (dense concrete) }\end{aligned}$ \\
\hline Wall thermal conductivity $\left(\mathrm{W} \mathrm{m}{ }^{-1} \mathrm{~K}^{-1}\right)$ & $\lambda_{\text {wall }, i}$ & $\begin{array}{l}i=1, \ldots, 9: 1.51 \text { (dense concrete) } \\
i=10: 0.03 \text { (insulation) }\end{array}$ \\
\hline Impervious road thermal conductivity $\left(\mathrm{W} \mathrm{m}^{-1} \mathrm{~K}^{-1}\right)$ & $\lambda_{\text {imprvrd }, i}$ & $\begin{array}{l}i=1,2: 0.82 \text { (asphalt/concrete) } \\
i=3, \ldots, 5: 2.10 \text { (stone aggregate) } \\
i=6, \ldots, 10: \text { soil texture }(50 \% \text { sand, } 40 \% \text { clay) }\end{array}$ \\
\hline Pervious road thermal conductivity $\left(\mathrm{W} \mathrm{m}^{-1} \mathrm{~K}^{-1}\right)$ & $\lambda_{\text {prvrd }, i}$ & Soil texture (50\% sand, $40 \%$ clay) \\
\hline Roof volumetric heat capacity $\left(\mathrm{MJ} \mathrm{m}^{-3} \mathrm{~K}^{-1}\right)$ & $c_{\text {roof }, i}$ & $\begin{array}{l}i=1, \ldots, 6: 1.76 \text { (gravel) } \\
i=7: 0.04 \text { (insulation) } \\
i=8, \ldots, 10: 2.11 \text { (dense concrete) }\end{array}$ \\
\hline Wall volumetric heat capacity $\left(\mathrm{MJ} \mathrm{m}^{-3} \mathrm{~K}^{-1}\right)$ & $c_{\mathrm{wall}, i}$ & $\begin{array}{l}i=1, \ldots, 9: 2.11 \text { (dense concrete) } \\
i=10: 0.04 \text { (insulation) }\end{array}$ \\
\hline Impervious road volumetric heat capacity $\left(\mathrm{MJ} \mathrm{m}^{-3} \mathrm{~K}^{-1}\right)$ & $c_{\text {imprvrd }, i}$ & $\begin{array}{l}i=1,2: 1.74 \text { (asphalt/concrete) } \\
i=3, \ldots, 5: 2.00 \text { (stone aggregate) } \\
i=6, \ldots, 10: \text { soil texture }(50 \% \text { sand, } 40 \% \text { clay) }\end{array}$ \\
\hline Pervious road volumetric heat capacity $\left(\mathrm{MJ} \mathrm{m}^{-3} \mathrm{~K}^{-1}\right)$ & $c_{\mathrm{prvrd}, i}$ & Soil texture ( $50 \%$ sand, $40 \%$ clay $)$ \\
\hline
\end{tabular}

Another possible reason is that the Oke relationship was developed from observed heat islands in over 30 North American and European cities whereas the model results are for a single location. The geographic location and prevailing meteorological conditions of the observed sites likely play a role in determining the heat island magnitude. For example, a maximum heat island of $12^{\circ} \mathrm{C}$ was observed for the city of Montreal, Canada, $(H / W=3.0)$ at midnight on 15 February 1970 when air temperatures were very low $\left(-20^{\circ} \mathrm{C}\right)$ and winds were nearly calm (Oke and East 1971). In general, the dependence of the heat island intensity on air temperature suggested that space heating played a major role. Indeed, Oke and East (1971) reported that the total heat released by combustion during the winter was $152 \mathrm{~W} \mathrm{~m}^{-2}$ averaged over the city. Thus it is not unreasonable to expect much higher anthropogenic fluxes on very cold days. As an example, our urban model produces a wintertime maximum heat island intensity of $12.5^{\circ} \mathrm{C}$ with anthropogenic fluxes and $10^{\circ} \mathrm{C}$ without anthropogenic fluxes when run with meteorological forcing appropriate for Montreal (modeled $H / W=3.0$ ) (not shown). The model predicts a total anthropogenic heat flux of about $200 \mathrm{~W} \mathrm{~m}^{-2}$ to achieve the maximum heat island intensity, which appears to be a reasonable flux in this context (the minimum air temperature for this simulated night is $-18^{\circ} \mathrm{C}$ ).

The heat island intensity is also likely to be a function of the characteristics of the rural surface (e.g., Hawkins et al. 2004). Figure 4 also shows the simulated heat island with a rural surface composed of needleleaf evergreen trees rather than grassland. Because the simu- lated forest is cooler than the grassland, the maximum heat island intensity simulated is nearly $12^{\circ} \mathrm{C}$, and a heat island intensity of $8^{\circ} \mathrm{C}$ is possible even at a heightto-width ratio of 0.5 .

The issues discussed here point out the fact that reproducing the Oke (1981) relationship with an urban model likely requires the explicit modeling of all conditions under which the relationship was developed. This includes the atmospheric forcing conditions and the morphological, radiative, and thermal properties of both urban and rural surfaces as well as anthropogenic influences. Feedbacks between the UCL and urban boundary layer also need to be accounted for, which could only be simulated in a coupled modeling system. However, the model does produce a significant urban heat island, one that increases with height-to-width ratio.

The energy balance of the urban site is very different from the rural site and explains the higher urban tem-

TABLE 3. Radiative input data required for the urban model. Albedos do not vary between direct and diffuse $(b)$ and visible and near infrared $(\Lambda)$.

\begin{tabular}{llc}
\hline \hline \multicolumn{1}{c}{ Data } & \multicolumn{1}{c}{ Symbol } & Default value \\
\hline Roof emissivity & $\varepsilon_{\text {roof }}$ & 0.90 \\
Impervious road emissivity & $\varepsilon_{\text {imprvrd }}$ & 0.94 \\
Pervious road emissivity & $\varepsilon_{\text {prvrd }}$ & 0.94 \\
Wall emissivity & $\varepsilon_{\text {wall }}$ & 0.85 \\
Roof albedo & $\alpha_{\text {roof, } \Lambda}^{b}$ & 0.15 \\
Wall albedo & $\alpha_{\text {walls, } \Lambda}^{b}$ & 0.25 \\
Impervious road albedo & $\alpha_{\text {imprvrd, } \Lambda}^{b}$ & 0.08 \\
Pervious road albedo & $\alpha_{\text {prvrd, } \Lambda}^{b}$ & 0.08 \\
\hline
\end{tabular}



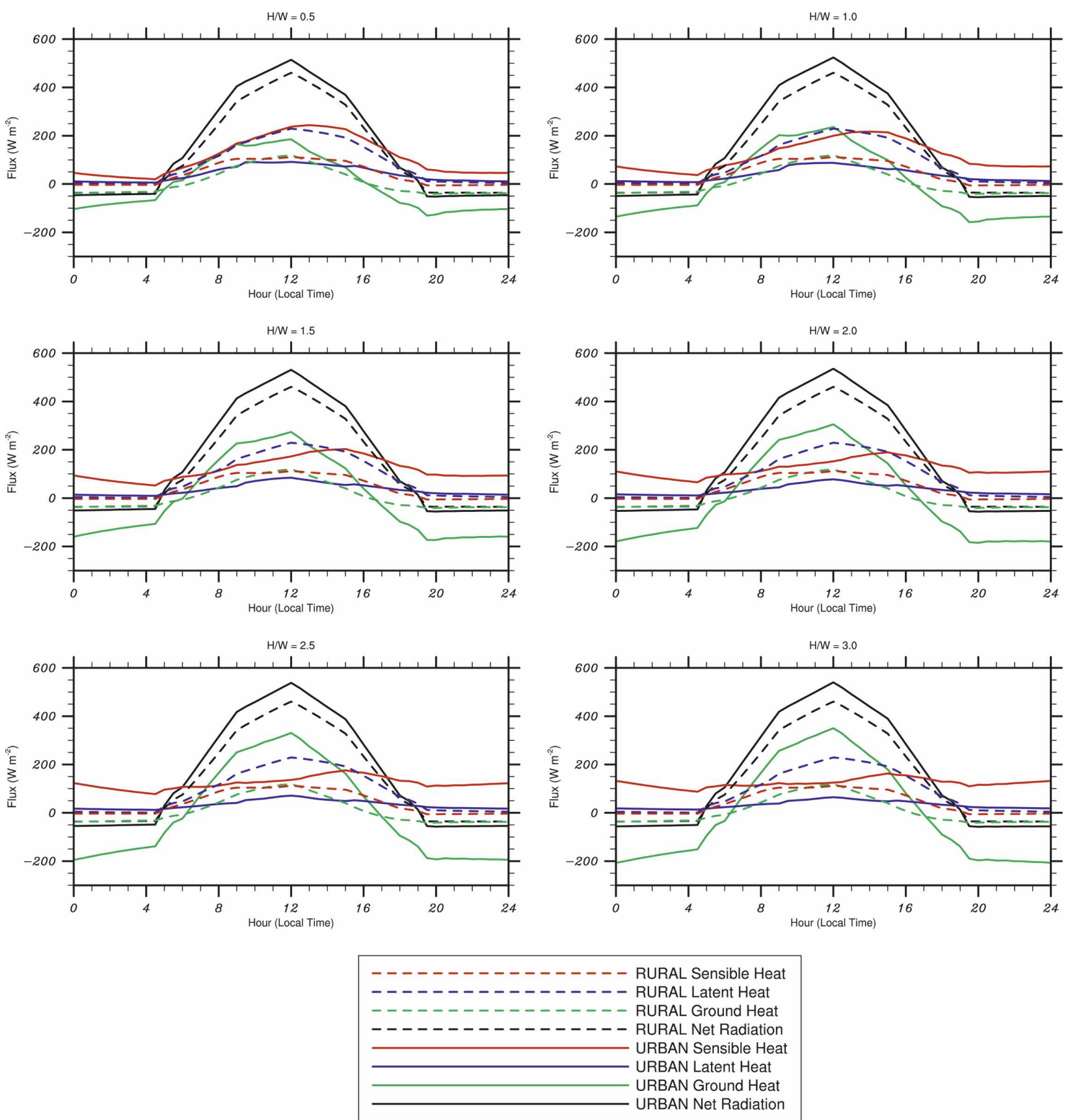

FIG. 5. Summer [June-August (JJA)] net radiation, ground heat, and sensible and latent heat fluxes produced by the urban model (without anthropogenic fluxes) in comparison with a grassland rural site, for a North American midlatitude location $\left(40^{\circ} \mathrm{N}, 75^{\circ} \mathrm{W}\right)$. Fluxes are positive away from the surface.

peratures. Figure 5 depicts the fluxes produced by the urban model in summer without anthropogenic fluxes [case "CLM3 (no anthro flux)" in Fig. 4] in comparison with rural grassland. The daytime urban net radiation is larger than the rural at all height-to-width ratios. This difference increases as height-to-width ratio increases. At a height-to-width ratio of 0.5 , the urban albedo is smaller than the rural albedo and consequently the urban surface absorbs more solar radiation. However, the increased solar absorption is offset somewhat by larger urban emitted longwave radiation due to higher surface temperatures. Urban net radiation is consequently 60 $90 \mathrm{~W} \mathrm{~m}^{-2}$ higher than rural net radiation during midday. 
The partitioning of daytime rural net radiation is dominated by latent heat, with sensible and storage heat flux being smaller components of the energy budget. In contrast, at a height-to-width ratio of 0.5 , the urban net radiation is taken up primarily by sensible and storage heat fluxes, with latent heat flux being a small component. Storage heat flux is nearly the same as sensible heat flux during the morning hours, whereas sensible heat flux begins to dominate in the early-tolate afternoon. At larger height-to-width ratios, storage heat flux becomes the dominant flux in the morning as heat is stored in the urban fabric and sensible heat becomes more important in the late afternoon as storage decreases and heat is released.

For the rural site at nighttime, the release of heat stored in the soil nearly balances the net radiative loss such that sensible and latent heat fluxes are nearly zero. The urban site has a release of heat greater than the net radiative loss such that a positive sensible heat flux is maintained throughout the night. As height-to-width ratio increases, more stored heat is released and larger fluxes of sensible heat are sustained. These features are in general agreement with energy balance features observed at many dry urban sites [e.g., as summarized by Grimmond and Oke (2002)].

To explore further the characteristics of the heat island generated by the model, a set of urban and rural simulations was conducted. A single rural simulation with multiple grid cells was conducted using hourly atmospheric forcing data for $1 \mathrm{yr}$ from the Community Atmosphere Model over the United States (Collins et al. 2006). Rural surface types were prescribed by the current CLM3 surface dataset at a resolution of $2.8^{\circ}$ longitude by $2.8^{\circ}$ latitude (Dickinson et al. 2006). An urban simulation was also run by replacing the rural surface types by a default model city (Tables 1,2 , and 3). The urban simulation was repeated for height-towidth ratios ranging from 0.5 to 3.0. Anthropogenic fluxes were not prescribed. The experimental setup is equivalent to running 115 one-dimensional rural and urban simulations with the urban simulations repeated at each height-to-width ratio. Thus, the variability of the heat island as a function of city density (as represented by height-to-width ratio) in a wide range of rural environments and climates can be examined. The following analyses are of course based on a single default city, and there are no feedbacks with the atmosphere; however, they serve as an example of the types of analyses that can be done to examine the effects of cities on climate within a coupled urban-climate modeling system.

Figure 6 shows that, as before, the average (over all grid cells) of the maximum heat island increases with height-to-width ratio in all seasons (long dashed line). Summer appears to have the strongest maximum heat island on average, followed by autumn and spring; winter has the weakest. However, for a given height-towidth ratio, a very wide range of maximum heat islands is simulated because of variability in climate and rural environment (denoted by the dots in Fig. 6). For example, at a height-to-width ratio of 3 , the maximum annual heat island varies from about $6^{\circ}$ to $13^{\circ} \mathrm{C}$ over all the climates found in the contiguous United States.

Urban effects on air temperature are generally thought to be larger at night than during the day, resulting in a reduced diurnal temperature range relative to rural surfaces (Karl et al. 1988; Gallo et al. 1996, 1999; Kalnay and Cai 2003). In a study using temperature data from the U.S. Historical Climatology Network, Karl et al. (1988) found that the reduction in diurnal temperature range associated with urban areas increased with population density. As shown in Fig. 6, the simulated urban-rural air temperature difference is larger for the daily minimum temperature as compared with the daily maximum, an effect that increases with height-to-width ratio (here we use height-to-width ratio as a proxy for population density). For a height-towidth ratio of 3.0 , the average diurnal temperature range for urban surfaces is reduced by $1.5^{\circ}-2.5^{\circ} \mathrm{C}$ relative to rural surfaces depending on the season (red line in Fig. 6). Karl et al. (1988) also found that urban effects on minimum and average temperature were stronger in summer and autumn than in winter and spring. Urban effects in spring were smallest. These simulations pro-

\footnotetext{
FIG. 6. Annual and seasonal (winter $=$ December-February; spring = March-May; summer = JJA; autumn = SeptemberNovember) characteristics of urban and rural air temperature differences. Urban and rural air temperatures ( $T_{\text {urban }}$ and $T_{\text {rural }}$, respectively) are from hourly data as described in the text. The lines indicate air temperature differences averaged over all grid cells. The daily maximum (blue line) is $\overline{T_{\text {urban, max }}-T_{\text {rural, max }}}$, where $T_{\text {urban,max }}$ and $T_{\text {rural,max }}$ are the maximum urban and rural air temperature in a given day and the overbar represents the average over the number of days in a given season. In a similar

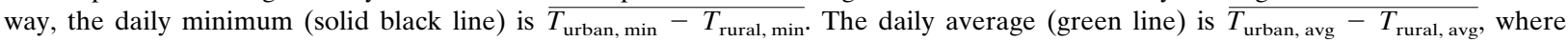
$T_{\text {urban,avg }}$ and $T_{\text {rural,avg }}$ are the daily average of the hourly urban and rural air temperatures. The daily average diurnal range (red line) is $\left(T_{\text {urban, max }}-T_{\text {urban, min }}\right)-\left(T_{\text {rural, max }}-T_{\text {rural, min }}\right)$. The daily average maximum (short-dashed line) represents the maximum heat island averaged over all days. The dots represent the maximum $T_{\text {urban }}-T_{\text {rural }}$ at each grid cell for a given height-to-width ratio, and the average of maximum (long-dashed line) represents the average of these at each height-to-width ratio.
} 
Annual

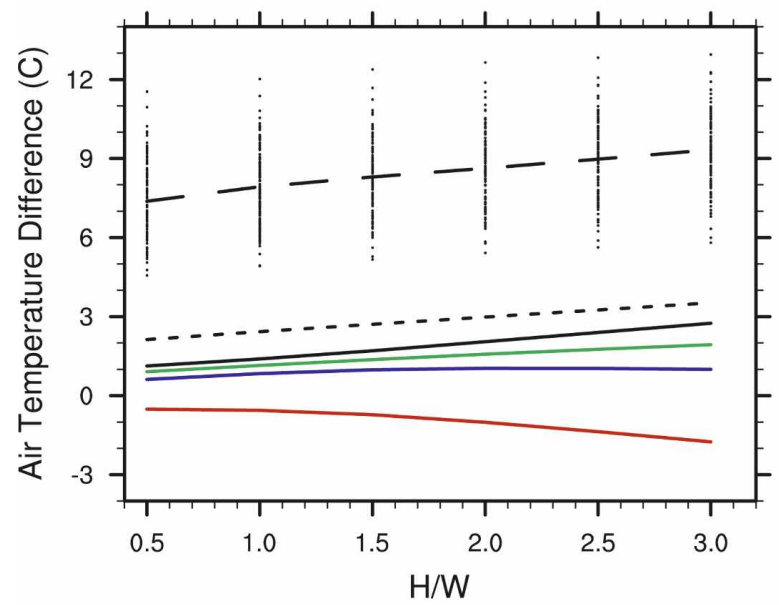

Spring

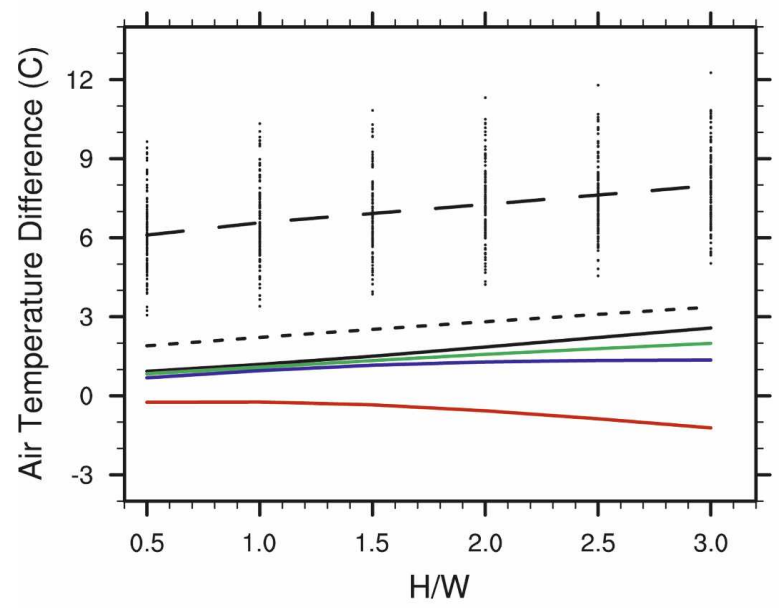

Fall

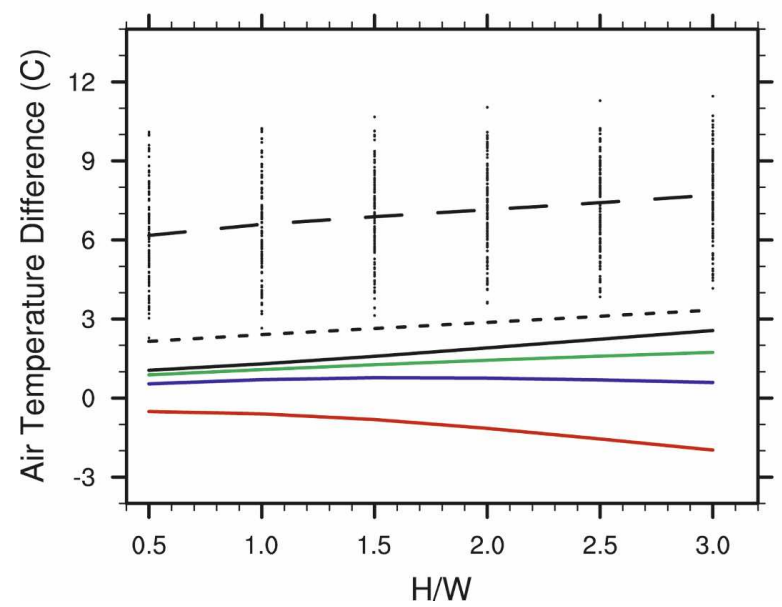

Winter

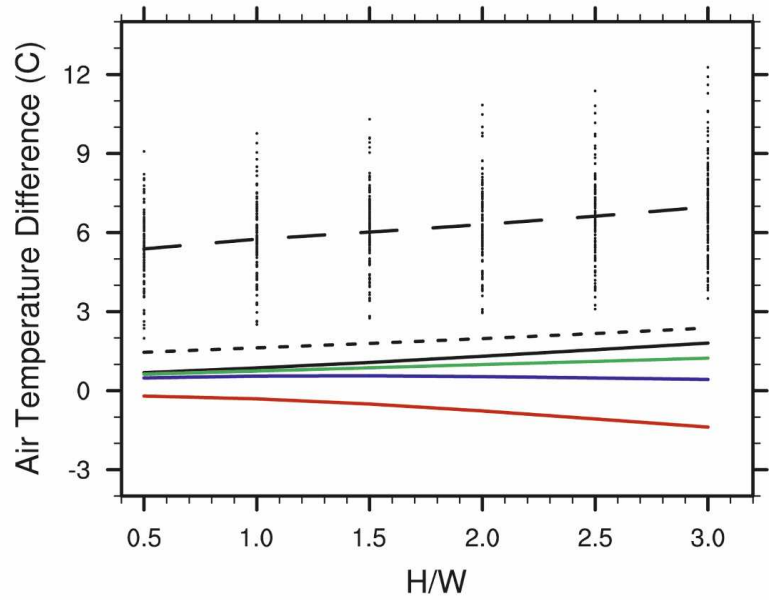

Summer

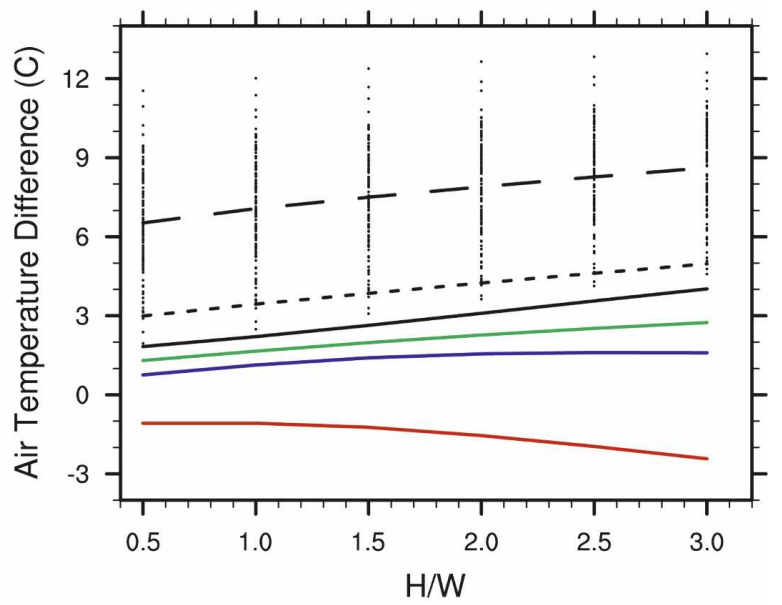

Average of Maximum Daily Average $\overline{\text { Maximum }}$ Daily Average Diurnal Range

\begin{tabular}{c}
\hline Daily Average \\
\hline Daily Minimum \\
\hline Daily Maximum \\
\hline
\end{tabular}




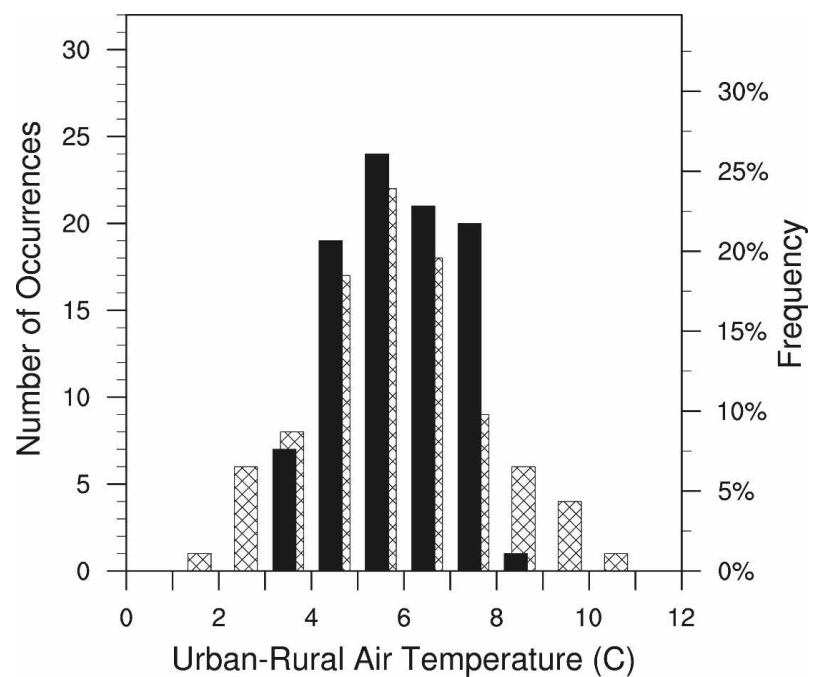

FIG. 7. Daily maximum heat island (urban minus rural air temperature) distribution for two grid cells with the same mean daily heat island in summer $(\mathrm{JJA})\left(5.8^{\circ} \mathrm{C}\right)$ with height-to-width ratio of 3.0. Solid bars refer to grid cell at $42.2^{\circ} \mathrm{N}, 92.2^{\circ} \mathrm{W}$, and hatched bars refer to grid cell at $33.8^{\circ} \mathrm{N}, 109^{\circ} \mathrm{W}$.

duce similar results, with urban effects being largest in summer and smallest in winter and about equal for spring and autumn. Karl et al. (1988) attributed the smaller effects in spring partly to the lower anthropogenic heating in spring as compared with winter. However, our study does not include anthropogenic fluxes, and therefore this explanation is not tested.

The daily average maximum heat island for all grid cells ranges from about $1.5^{\circ}$ to $5^{\circ} \mathrm{C}$, depending on height-to-width ratio and season (short dashed line in Fig. 6). However, when considering urban effects on the comfort levels of the human population, it is also important to consider the timing of urban heat islands along with their magnitude. These characteristics may also have implications for energy consumption. The range of daily heat islands can be very different, even for locations that have the same mean heat island, as is shown by a comparison of two grid cells in the Midwestern and Southwestern United States (Fig. 7). The Southwest grid cell has a wider distribution of heat islands when compared with the Midwest grid cell, with $14 \%$ of the daily heat islands greater than $8^{\circ} \mathrm{C}$, but also with more instances of heat islands less than $3^{\circ} \mathrm{C}$.

As mentioned above, studies indicate the maximum heat island generally occurs at night. However, the timing of the maximum heat island may vary depending on local conditions. For example, Oke and Maxwell (1975) found that the maximum heat island in Montreal and Vancouver occurred 3-5 h after sunset. Jáuregui (1997) found that the heat island in Mexico City increased throughout the night, resulting in a maximum just be-

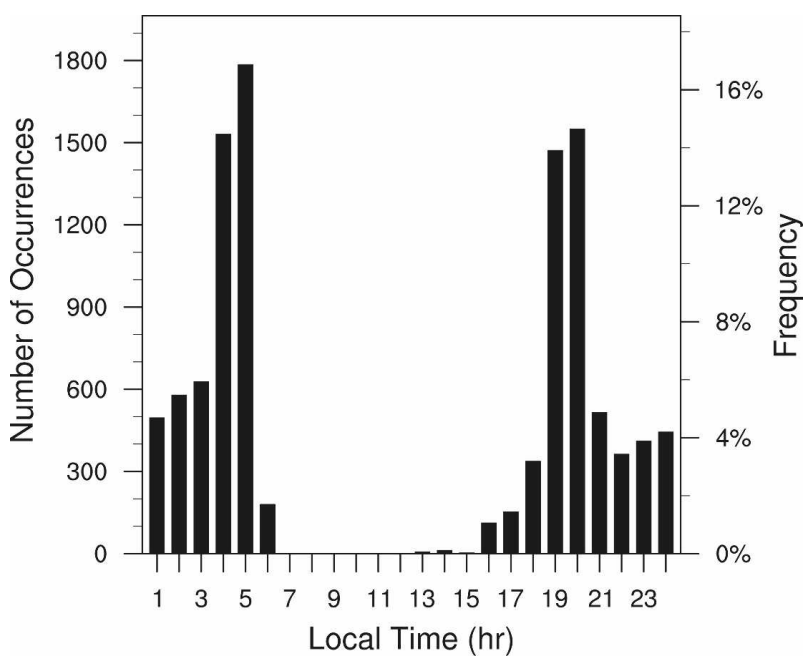

FIG. 8. Time of daily maximum heat island (urban minus rural air temperature) in summer (JJA) for the United States with height-to-width ratio of 3.0.

fore sunrise. Fortuniak et al. (2005) found that the heat island in Lodz, Poland, increased until about midnight and then remained fairly constant until sunrise. The maximum heat island could occur at any time during the stabilization stage. The timing of the daily maximum heat island in summer for a height-to-width ratio of 3.0 varies considerably in our simulations over the entire United States (Fig. 8). It is clear that the maximum heat island occurs during nighttime hours in almost all cases (sunset for the United States in summer occurs approximately between 1840 and 1950 local time, and sunrise is between 0430 and 0540). Most heat islands occur near sunset or near sunrise $(60 \%)$. However, about $40 \%$ occur at other times of the night.

The timing of the maximum heat island is related to the relative cooling rates of rural and urban surfaces. Figure 9 shows the average cooling rates for two grid cells in summer with disparate heat island characteristics. For a grid cell in a southern U.S. location (Fig. 9a), the heat island intensity is relatively low and begins to increase just before sunset and reaches a maximum about $4 \mathrm{~h}$ after sunset. This is caused by the fact that the urban and rural cooling rates are similar until just before sunset, at which time the rural surface cools faster than the urban. Later, the cooling rate of the rural surface begins to approach the cooling rate of the urban surface and the atmosphere and the maximum heat island is reached. In contrast, the rural surface for a more northerly mountain area (Fig. 9b) cools much faster than the urban surface and there is a rapid rise in the heat island. Relative to the previous case, the rural cooling rate remains stronger than the urban rate and the heat island increases throughout the night, reaching 

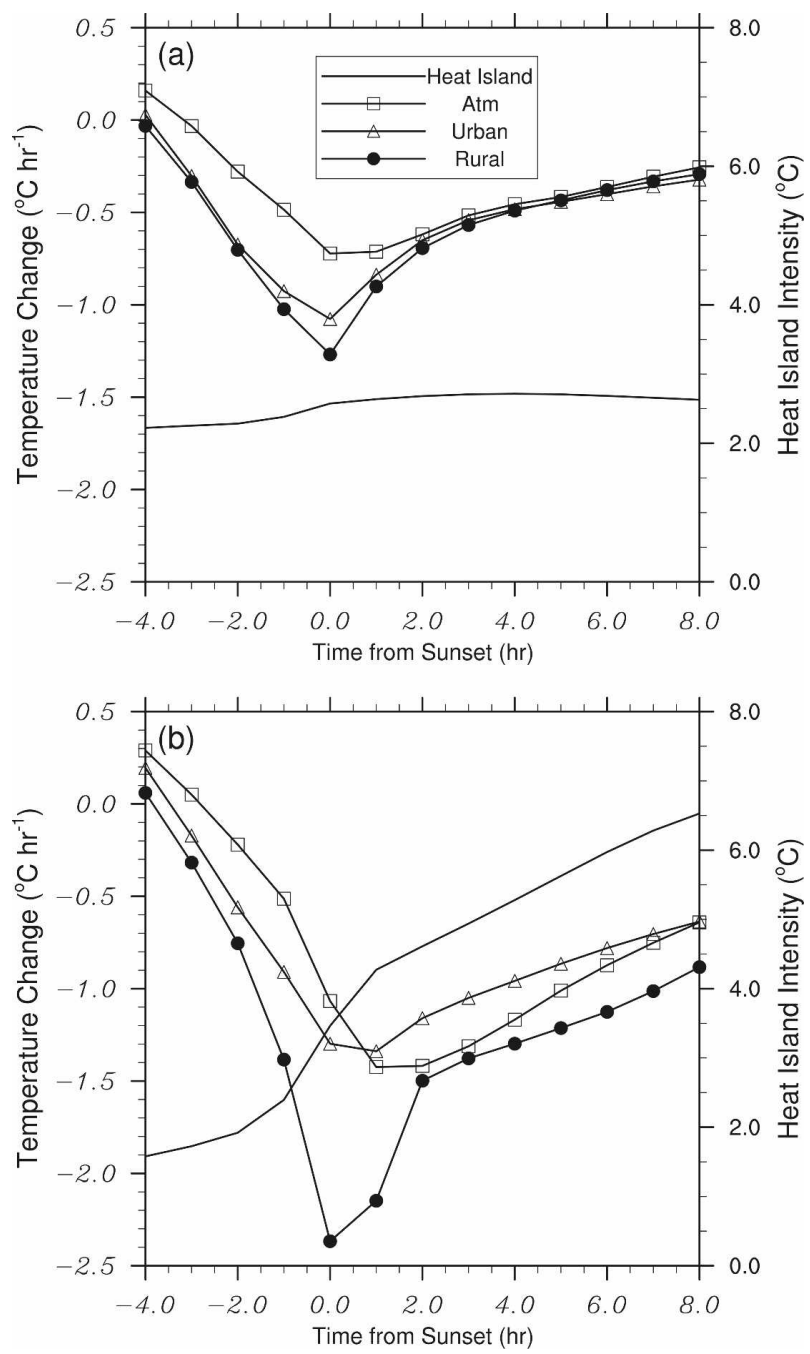

FIG. 9. Temperature change of urban $(H / W=3.0)$ and rural surfaces and the resulting heat island (urban minus rural air temperature) in summer (JJA) for grid cells at (a) $28.2^{\circ} \mathrm{N}, 114.6^{\circ} \mathrm{W}$ and (b) $36.6^{\circ} \mathrm{N}, 114.6^{\circ} \mathrm{W}$.

a maximum near sunrise. Both rural sites are dominated by broadleaf deciduous shrub with very small leaf and stem area, so that the soil characteristics control the temperature response. The northern rural site is much drier than the southern rural site so that it has lower thermal admittance. This means the northern site cannot release heat fast enough to offset the surface radiative loss (not shown). That and the fact that the atmospheric cooling rate is larger probably explain why the northern rural site cools at a faster rate than the southern site.

The urban surface is characterized by a preponderance of impervious surfaces, which reduce water storage capacity and surface moisture availability (Oke 1982). However, urban surfaces may have varying amounts of evaporating surfaces that can influence the

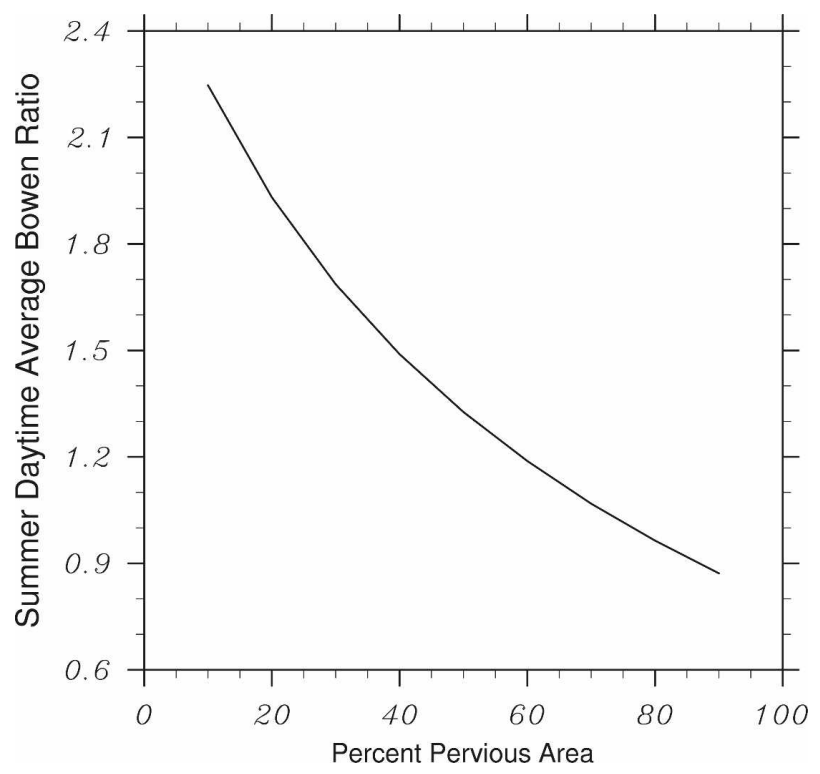

FIG. 10. Simulated summer (JJA) daytime average Bowen ratio as a function of percent pervious area for a default North American city $\left(40^{\circ} \mathrm{N}, 75^{\circ} \mathrm{W}\right)$ with height-to-width ratio of 0.5 .

energy balance, temperatures, and humidity. For example, a study of four U.S. cities by Grimmond and Oke (1995) showed that the Bowen ratio decreases as irrigated green space increases. The presence of evaporating surfaces can also decrease the magnitude of the heat island effect (Upmanis et al. 1998; Sailor 1995; Avissar 1996). Our simulations show that the summer daytime Bowen ratio is strongly correlated with the percent pervious area (Fig. 10; note that here the percent pervious area is with respect to the area occupied by the canyon floor). With small pervious area, the sensible heat flux is more than 2 times the latent heat flux. As pervious area increases, latent heat flux increases, sensible heat decreases, and the Bowen ratio decreases, dropping below a value of 1 at about $75 \%$ pervious area. The range of Bowen ratios shown here compare reasonably to those found by Grimmond and Oke (1995).

Urban temperature characteristics are also affected by the inclusion of pervious area (Fig. 11). Pervious area increases the latent heat flux from the urban system and lowers UCL air temperatures. The amount that temperatures are lowered depends on the amount of latent heat which in turn depends on soil moisture availability. Changes in the daily maximum heat island and the maximum and minimum urban temperatures are all strongly inversely correlated with changes in latent heat ( $r=-0.69,-0.91$, and -0.62 , respectively). The strongest effect is on maximum temperatures $\left[-0.1^{\circ} \mathrm{C}\left(100 \mathrm{~W} \mathrm{~m}^{-2}\right)^{-1}\right]$ rather than on minimum temperatures $\left[-0.07^{\circ} \mathrm{C}\left(100 \mathrm{~W} \mathrm{~m}^{-2}\right)^{-1}\right]$ or on the maxi- 

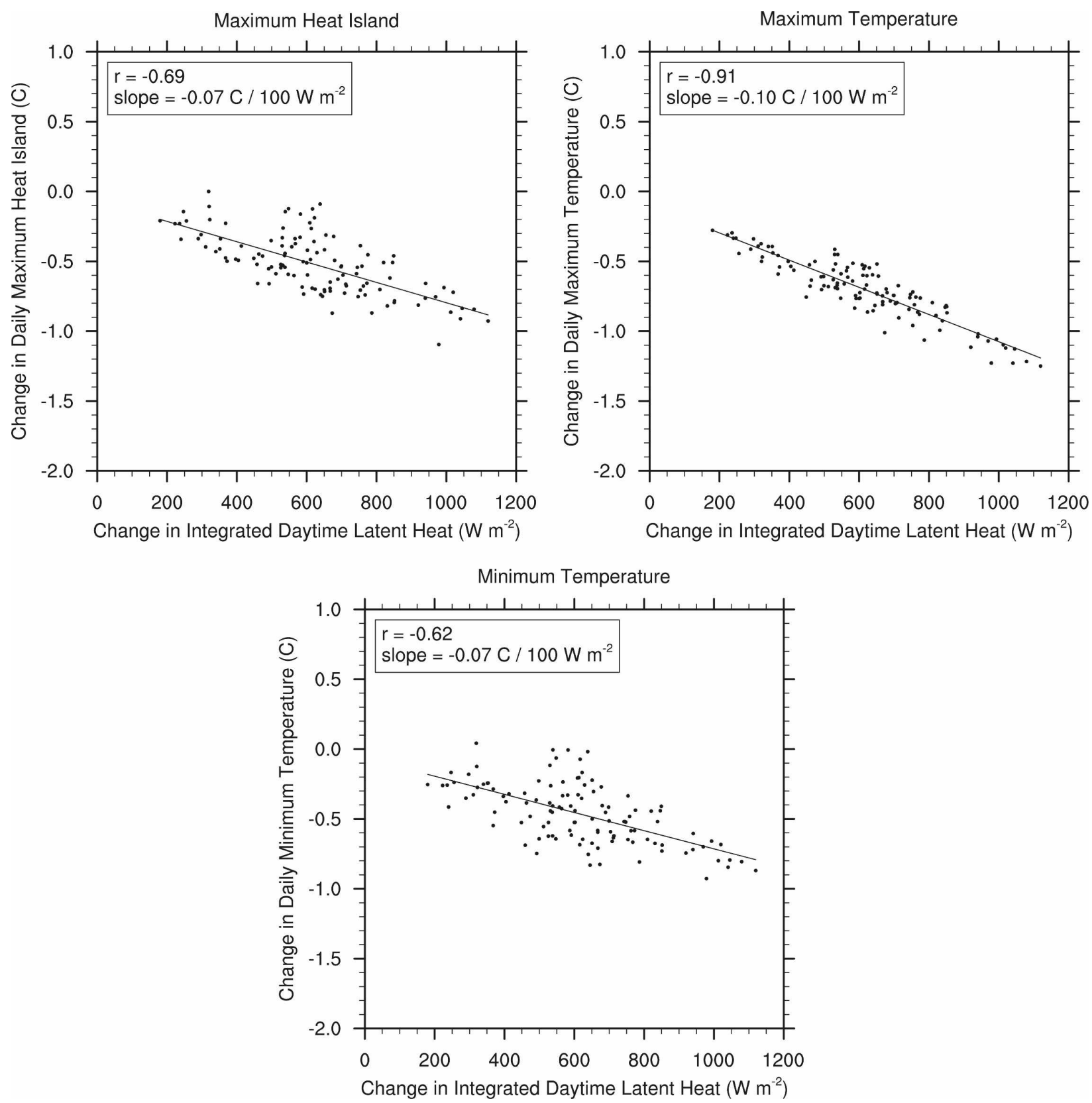

FIG. 11. Average urban temperature characteristics in summer as a function of summed hourly daytime latent heat flux. The change in urban temperature characteristic (i.e., daily maximum heat island, daily maximum temperature, and daily minimum temperature) is defined as the difference between a simulation with height-to-width ratio of 3.0 and pervious area of $80 \%$ and a simulation with the same height-to-width ratio but with zero pervious area. There are 115 points plotted in each panel, each representing one grid cell.

mum heat island $\left[-0.07^{\circ} \mathrm{C}\left(100 \mathrm{~W} \mathrm{~m}^{-2}\right)^{-1}\right]$, because latent heat fluxes have the most effect in daytime.

\section{Summary and conclusions}

The formulation and evaluation of an urban model designed for the land surface component of a global climate model was described in Part I. In the current paper, the urban model was further tested through sensitivity studies and a qualitative examination of the characteristics of the simulated urban heat islands. The storage and sensible heat flux are most sensitive to uncertainties in the input parameters, at least within the range of atmospheric and surface conditions considered 
here. Latent heat flux was found to be generally insensitive to all parameters, primarily because it is a small part of the energy balance at the sites tested. A comparison of simulations of Vancouver and Mexico City shows that sites with larger pervious area would show larger sensitivity of latent heat flux to parameter uncertainty-in particular, morphological ones (e.g., height-to-width ratio, roof fraction, pervious road fraction, or building height). Net radiation also showed little sensitivity to the input parameters.

The sensible and storage heat fluxes were equally sensitive to morphological and thermal parameters and were least sensitive to radiative parameters. This suggests that not only should attention be paid to characterizing accurately the structure of the urban area (e.g., height-to-width ratio), but the input data should also fairly accurately reflect the thermal admittance of each of the city surfaces (e.g., roof and walls). However, it should be recognized that it is specific combinations of parameter perturbations that cause the largest responses in the model. For example, underestimates of height-to-width ratio and roof and wall thicknesses in combination with an overestimate of roof fraction will have the largest effect on the simulated amplitude of the diurnal cycle of sensible heat flux. Other combinations of parameter uncertainty tend to offset each other and reduce the sensitivity of sensible heat flux. In a similar way, the largest responses of sensible and storage heat fluxes result from under- or overestimating the thermal admittance of all surfaces in combination (roof, walls, road).

The analyses in Part I and the current paper show that the model performance in simulating the average diurnal cycle of net radiation and sensible and storage heat flux is reasonable using the selected parameter values. The sensitivity simulations show that not much improvement can be gained by optimizing the input parameters with respect to the surface fluxes. In general, parameter uncertainty mainly affects the amplitude of the diurnal cycle and not the phase. Some improvement can be realized in the simulation of the amplitude of the sensible heat diurnal cycle, but the simulation of the storage heat flux is degraded. This result implies that further improvement in the model's performance would require changes to the physical parameterizations in the urban model. Given the reasonably good performance of the model for the two sites tested, further investigation using other urban datasets is required to see whether any such changes are justified.

Urban heat island simulations show that the urban model appears to be capable of capturing some observed effects of urban characteristics on climate in a qualitative sense. In particular, the model produces a significant heat island that increases with height-towidth ratio. Storage and sensible heat flux are the primary responses to net radiation for urban surfaces. Storage becomes increasingly important as height-towidth ratio increases. The urban model maintains a positive sensible heat flux at night because the release of stored heat exceeds the net radiative loss. The daily minimum temperature increases more than the daily maximum temperature for urban surfaces resulting in a reduced diurnal temperature range relative to a rural environment. The magnitude, frequency distribution, and timing of the heat island vary tremendously depending on the prevailing meteorological conditions and the surrounding rural environment. Increasing pervious area within the urban canyon reduces the Bowen ratio and canopy air temperatures of the urban system, thereby decreasing the heat island effect.

The results presented in Part I and the current paper suggest that the model appears to be a useful tool for investigating urban climatology within the framework of global climate models. How urban climate characteristics might change with climate change is an important future research question with societal implications that can be explored using the model.

Acknowledgments. We gratefully acknowledge C. S. B. Grimmond for providing the Mexico City and Vancouver observations and for useful discussions. This research was supported by the Office of Science (BER), U.S. Department of Energy, Cooperative Agreement DE-FC02-97ER62402, the National Science Foundation Grants ATM-0107404 and ATM0413540, the National Center for Atmospheric Research Water Cycles Across Scales, Biogeosciences, and Weather and Climate Impacts Assessment Science Initiatives, and the University of Kansas, Center for Research. We thank three anonymous reviewers for comments leading to substantial improvements in the manuscript.

\section{REFERENCES}

Arnfield, A. J., 2000: A simple model of urban canyon energy budget and its validation. Phys. Geogr., 21, 305-326.

_ 2003: Two decades of urban climate research: A review of turbulence, exchanges of energy and water, and the urban heat island. Int. J. Climatol., 23, 1-26.

Avissar, R., 1996: Potential effects of vegetation on the urban thermal environment. Atmos. Environ., 30, 437-448.

Best, M. J., 2005: Representing urban areas within operational numerical weather prediction models. Bound.-Layer Meteor., 114, 91-109.

Bonan, G. B., 2002: Ecological Climatology: Concepts and Applications. Cambridge University Press, $678 \mathrm{pp}$.

_ S. Levis, L. Kergoat, and K. W. Oleson, 2002: Landscapes as 
patches of plant functional types: An integrating concept for climate and ecosystem models. Global Biogeochem. Cycles, 16, 1021, doi:10.1029/2000GB001360.

Collins, W. D., and Coauthors, 2006: The formulation and atmospheric simulation of the Community Atmosphere Model Version 3 (CAM3). J. Climate, 19, 2144-2161.

Dickinson, R. E., K. W. Oleson, G. B. Bonan, F. Hoffman, P. Thornton, M. Vertenstein, Z.-L. Yang, and X. Zeng, 2006: The Community Land Model and its climate statistics as a component of the Community Climate System Model. J. Climate, 19, 2302-2324.

Fortuniak, K., K. Klysik, and J. Wibig, 2005: Urban-rural contrasts of meteorological parameters in Łódź. Theor. Appl. Climatol., 84, 91-101.

Gallo, K. P., D. R. Easterling, and T. C. Peterson, 1996: The influence of land use/land cover on climatological values of the diurnal temperature range. J. Climate, 9, 2941-2944.

—, T. W. Owens, D. R. Easterling, and P. F. Jamason, 1999: Temperature trends of the U.S. Historical Climatology Network based on satellite-designated land use/land cover. $J$. Climate, 12, 1344-1348.

Grimmond, C. S. B., and T. R. Oke, 1995: Comparison of heat fluxes from summertime observations in the suburbs of four North American cities. J. Appl. Meteor., 34, 873-889.

$\longrightarrow$, and — 2002: Turbulent heat fluxes in urban areas: Observations and a local-scale urban meteorological parameterization scheme (LUMPS). J. Appl. Meteor., 41, 792-810.

Hawkins, T. W., A. J. Brazel, W. L. Stefanov, W. Bigler, and E. M. Saffell, 2004: The role of rural variability in urban heat island determination for Phoenix, Arizona. J. Appl. Meteor., 43, 476-486.

Jáuregui, E., 1997: Heat island development in Mexico City. Atmos. Environ., 31, 3821-3831.

Kalnay, E., and M. Cai, 2003: Impact of urbanization and land-use change on climate. Nature, 423, 528-531.

Karl, T. R., H.F. Diaz, and G. Kukla, 1988: Urbanization: Its detection and effect in the United States climate record. $J$. Climate, 1, 1099-1123.

Landsberg, H. E., 1981: The Urban Climate. Academic Press, 275 pp.

Martilli, A., A. Clappier, and M. W. Rotach, 2002: An urban surface exchange parameterization for mesoscale models. Bound.-Layer Meteor., 104, 261-304.

Masson, V., 2000: A physically-based scheme for the urban energy budget in atmospheric models. Bound.-Layer Meteor., 94, 357-397.

, C. S. B. Grimmond, and T. R. Oke, 2002: Evaluation of the Town Energy Balance (TEB) scheme with direct measurements from dry districts in two cities. J. Appl. Meteor., 41, 1011-1026.
Oke, T. R., 1973: City size and the urban heat island. Atmos. Environ., 7, 769-779.

_ 1976: The distinction between canopy and boundary-layer heat islands. Atmos. Environ., 14, 268-277.

_ 1981: Canyon geometry and the nocturnal urban heat island: Comparison of scale model and field observations. J. Climatol., 1, 237-254.

- 1982: The energetic basis of the urban heat island. Quart. J. Roy. Meteor. Soc., 108, 1-24.

_- 1987: Boundary Layer Climates. 2nd ed. Methuen, 435 pp. , 1988: The urban energy balance. Prog. Phys. Geogr., 12, 471-508.

, and C. East, 1971: The urban boundary layer in Montreal. Bound.-Layer Meteor., 1, 411-437.

_, and G. B. Maxwell, 1975: Urban heat island dynamics in Montreal and Vancouver. Atmos. Environ., 9, 191-200.

— , G. T. Johnson, D. G. Steyn, and I. D. Watson, 1991: Simulation of surface urban heat islands under 'ideal' conditions at night. Part 2: Diagnosis of causation. Bound.-Layer Meteor., 56, 339-358.

— 1999: The energy balance of central Mexico City during the dry season: Matching scales of observations and fluxes. Atmos. Environ., 33, 3919-3930.

Oleson, K. W., and Coauthors, 2004: Technical description of the Community Land Model (CLM). NCAR Tech. Note NCAR/ TN-461+STR, 173 pp.

— G. B. Bonan, J. Feddema, M. Vertenstein, and C. S. B. Grimmond, 2008: An urban parameterization for a global climate model. Part I: Formulation and evaluation for two cities. J. Appl. Meteor. Climatol., 47, 1038-1060.

Sailor, D. J., 1995: Simulated urban climate response to modifications in surface albedo and vegetative cover. J. Appl. Meteor., 34, 1694-1704.

— diurnal and seasonal anthropogenic heating profiles for urban areas. Atmos. Environ., 38, 2737-2748.

Taylor, K. E., 2001: Summarizing multiple aspects of model performance in a single diagram. J. Geophys. Res., 106, 7183 7192.

Terjung, W. H., and P. A. O'Rourke, 1980: Simulating the causal elements of urban heat islands. Bound.-Layer Meteor., 19, 93-118.

Upmanis, H., I. Eliasson, and S. Lindqvist, 1998: The influence of green areas on nocturnal temperatures in a high latitude city (Göteborg, Sweden). Int. J. Climatol., 18, 681-700.

Voogt, J. A., and C. S. B. Grimmond, 2000: Modeling surface sensible heat flux using surface radiative temperatures in a simple urban area. J. Appl. Meteor., 39, 1679-1699. 